\title{
Knowledge of a cancer diagnosis is a protective factor for the survival of patients with breast cancer: a retrospective cohort study
}

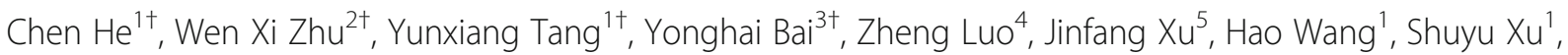
Jingzhou Xu' ${ }^{1}$ Lei Xiao ${ }^{1}$, Ruike Zhang ${ }^{1}$, Yajing Wang ${ }^{1}$, Jing Du', Yujia Huang ${ }^{1}$, Xiaopan Li $^{6,7^{*}}$ and Tong Su ${ }^{*^{*}}$ (D)

\begin{abstract}
Background: The health burden of breast cancer is rising in China. The effect of informed diagnosis on long-term survival is not fully understood. This retrospective cohort study aims to explore the association between early informed diagnosis and survival time in breast cancer patients.

Methods: A total of 12,327 breast cancer patients were enrolled between October 2002 and December 2016. Potential factors, including knowing the cancer diagnosis status, sex, age, clinical stage, surgery history, grade of reporting hospital and diagnostic year were, analyzed. We followed up all participants every 6 months until June 2017. Propensity score matching (PSM) was used to balance the clinicopathologic characteristics between patients who knew their diagnosis and those who did not.
\end{abstract}

Results: By June 2017, 18.04\% of the participants died of breast cancer. Before PSM, both the 3-year and 5-year survival rates of patients who knew their cancer diagnosis were longer $(P<0.001)$. After PSM, the above conclusion was still established. By stratified analysis, except for the subgroups of male patients and stage III patients, patients who knew their diagnosis showed a better prognosis in all the other subgroups $(P<0.05)$. Cox regression analysis showed that knowing a cancer diagnosis was an independent risk factor for survival in breast cancer patients $(P<0.001)$.

Conclusions: Being aware of their cancer diagnosis plays a protective role in extending the survival time of breast cancer patients, which suggests that medical staff and patients' families should disclose the cancer diagnosis to patients in a timely manner. Further prospective studies need to be made to validate our findings.

Keywords: Breast cancer, Diagnosis disclosure, Prognosis, Follow-up, Survival, Retrospective cohort study

\footnotetext{
* Correspondence: xiaopanli0224@126.com; sutong-2006@163.com

${ }^{+}$Chen He, Wen Xi Zhu, Yunxiang Tang and Yonghai Bai contributed equally

to this work.

${ }^{6}$ Department of Cancer Prevention and Vital Statistics, Center for Disease

Control and Prevention, Pudong New Area, Shanghai, China

'Department of Medical Psychology, College of Psychology, Naval Medical

University, 800 Xiangyin Rd, Shanghai 200433, China

Full list of author information is available at the end of the article
}

C C The Author(s). 2021 Open Access This article is licensed under a Creative Commons Attribution 4.0 International License, which permits use, sharing, adaptation, distribution and reproduction in any medium or format, as long as you give appropriate credit to the original author(s) and the source, provide a link to the Creative Commons licence, and indicate if changes were made. The images or other third party material in this article are included in the article's Creative Commons licence, unless indicated otherwise in a credit line to the material. If material is not included in the article's Creative Commons licence and your intended use is not permitted by statutory regulation or exceeds the permitted use, you will need to obtain permission directly from the copyright holder. To view a copy of this licence, visit http://creativecommons.org/licenses/by/4.0/. The Creative Commons Public Domain Dedication waiver (http://creativecommons.org/publicdomain/zero/1.0/) applies to the data made available in this article, unless otherwise stated in a credit line to the data. 


\section{Background}

Breast cancer, lung cancer, and colon cancer are the three most common cancers worldwide. One in eight to ten women will develop breast cancer during their lifetime [1]. Based on the National Cancer Institute (NCI)'s Surveillance, Epidemiology, and End Results (SEER) program of the United States, the incidence of breast cancer among women aged 20 to 39 years increased from 24.6/ 1000,000 to $31.7 / 100,000$ from 1975 to 2015 . The 5 -year survival increased from 74.0 to $88.5 \%$ [2]. However, breast cancer continues to be the most common cause of female death in developing countries and second to lung cancer in developed countries. Especially in South America, Africa, and Asia, the incidence of breast cancer is increasing instead of decreasing [3].

Since the 1990s, the incidence of breast cancer in China has increased more than twice as fast as the global rates, particularly in urban areas [4]. By 2008, China accounted for $12.2 \%$ of global cases of invasive breast cancer and $9.6 \%$ of the related deaths [5]. It is anticipated that the cases of breast cancer in China will increase from less than 60 cases per 100,000 women aged 55-69 years to more than 100 cases per 100,000 women, reaching 2.5 million cases overall by 2021 [6].

The patterns of breast cancer risk in Chinese women are partly aligned with known risk factors for women in developed countries [7]. Reproductive and hormonal factors such as nulliparity, increased age at first live birth, and limited breastfeeding are associated with an increased risk of breast cancer in the Chinese population, which is similar to Western women [8-10]. The one-child policy in China, it might have affected breast cancer risk by reducing the lifetime duration of breastfeeding [8]. Obesity and low levels of physical activity are both known as risk factors for breast cancer in Western countries. With the rapid growth of finance in China, these factors may also be risk factors for breast cancer in China [11]. Other factors, such as height, hormone replacement therapy, and family history, have also been regarded as risk factors for breast cancer in Chinese women $[11,12]$. However, few studies have paid attention to psychological factors, such as the association between cancer diagnosis disclosure and the survival time of patients with breast cancer.

People display different attitudes towards life as their age grows. Some studies found that patients of different ages may display different emotional experiences. Although the incidence of breast cancer increases with age, younger patients may be more likely to suffer emotional distress than older patients. This relationship can be observed in patients ranging in age from 30 to over 80 years [13, 14]. Additionally, another study reported a nonsignificant correlation between age and affective distress by examining the above association 10 months after diagnosis [15]. Most studies had a limited sample size, which may affect the effectiveness of the conclusions.

Whether to fully inform patients of their cancer diagnosis has traditionally been a controversial topic. Advocates of concealing the condition to patients argue that patients who know their cancer diagnosis are liable to experience significant distress, which may lead to a worse prognosis [16]. Studies in Iran and Turkey showed that patients who knew their diagnosis were more likely to undergo depression, psychiatric morbidity and other negative emotions $[17,18]$. On the other hand, patients who lack the awareness of their condition may have unrealistic optimism, which may lead to unfavourable behaviours and finally result in adverse health outcomes [19]. Previous studies showed that having an appropriate perspective of cancer status improved patients' participation in the treatment and reduced their distress level, which helped them meet their psychological needs with self-esteem and respect [20]. In contrast, another study among elderly patients mentioned that not knowing their cancer condition results in an incomplete understanding of their diagnosis, which would hurt the trust relationship between these patients and physicians [21]. Based on a study of a total of 127 cancer patients and their caregivers, no significant difference was found before and after disclosing the cancer diagnosis to patients, while the quality of life could be improved with psychological care intervention [22]. We found that in patients with lung cancer, those who knew their cancer status had a better survival rate, while there are few studies about this issue in breast cancer patients [23].

The association between the diagnostic disclosure of breast cancer and the prognosis of patients was explored in this retrospective cohort study based on the baseline and long-term follow-up information of a large sample. The results may provide valuable evidence for clinical practice.

\section{Methods}

The study was designed to determine the role that knowledge of the cancer diagnosis plays in the survival rate of patients with breast cancer by collecting information on patients with different backgrounds. Cancer disclosure was defined as informing patients of their cancer diagnosis. Patient knowledge of treatment, prognosis, and other relevant information was not considered.

\section{Participants}

A total of 12,327 patients who were diagnosed with breast cancer between October 2002 and December 2016 were included in this study. All participants were registered at certified hospitals in Pudong New Area, Shanghai, China. This study followed the Helsinki 
Declaration of 1975. Written informed consent was obtained from the participants or their families.

\section{Data collection}

The knowledge status of the cancer diagnosis of participants was collected at the time of study enrolment by the Shanghai Tumor Registry in accordance with Shanghai Tumor Report Card (Additional file 1). Information on demographics, breast cancer diagnosis, clinical stage and other relevant data was collected at the same time. The registration of cancer was conducted according to the criteria of the Chinese Guideline for Cancer Registration [24] and Cancer Incidence in Five Continents Volume IX [25]. The population data of cancer patients registered in the Shanghai Cancer Registry system were obtained from the Public Security Bureau of Pudong, Shanghai, China. The proportion of morphological verification (MV\%), percentage of cancer cases identified with death certification only (DCO\%), and mortality-toincidence ratio $(\mathrm{M} / \mathrm{I})$ were 3 major measures to evaluate the primary exposures $[26,27]$. We analysed the diagnosis based on the hospitalization medical record, which recorded whether the medical staff at that time had informed the patient of their cancer status. Centers for Disease Control staff regularly obtain information on cancer deaths from the Cause of Death Registration and Reporting System to determine the number of cancer deaths. Few patients were registered after death, and their knowledge status of cancer diagnosis was unclear. The survival data of patients with breast cancer were collected through the Centers for Disease Control and Prevention of the Pudong New Area, Shanghai. Community doctors followed up the patients by telephone calls or household surveys every 6 months, and regarded death as the primary outcome event. The follow-up ended in June 2017.

\section{Statistical analysis}

The $\chi^{2}$ test was used to explore all categorical variables. One-way analysis of variance (ANOVA) was conducted to compare continuous variables. A life table was used to calculate the 3-year survival rate and 5-year survival rate and to compare the differences in the survival curves between subgroups. We included knowledge of cancer diagnosis status, sex, age, clinical stage, surgery history, diagnostic year and reporting hospital grade in the Cox proportional hazards regression model (forward stepwise, likelihood ratio test). The Cox proportional hazards regression model (forward stepwise, likelihood ratio test) with hazard ratios (HRs) and 95\% confidence intervals (CIs) calculated was used to conduct multivariate analysis of factors influencing survival time. As shown in Additional file 2, the transformed KaplanMeier curves by the year of diagnosis displayed a graphical check for the proportionality of hazards. The assumptions of proportionality were met for the Cox models. Statistical Package for Social Sciences software (version 23.0, SPSS, Inc., Chicago, IL) was used to conduct all statistical analyses, and all tests were two-sided. $P<0.05$ was defined as statistically significant.

\section{Propensity score matching (PSM)}

We generated propensity scores (PSs) from a logistic regression model described by Rosenbaum and Rubin [28]. Sex, age, clinical stage, surgery history, the grade of reporting hospital and diagnostic year were included as covariates, which were selected into the model to optimize the matching procedure. In our retrospective study, each patient in the subgroup who knew of their diagnosis was 1:1 matched, with a calliper value of 0.02 , to a corresponding patient in the subgroup who had no idea of their diagnosis by selecting the same PS for each pair. The 3-year survival rate and 5-year survival rate were calculated by a life table, and we compared the differences in the survival curves between the above subgroups.

\section{Results \\ Baseline characteristics}

A total of 12,327 patients with breast cancer were enrolled in this study. Table 1 shows the baseline characteristics of the participants. Among all 12,327 participants, 9466 (76.79\%) patients were aware of their cancer diagnosis, and 2756 (22.36\%) patients had no idea of their situation. There were $105(0.85 \%)$ patients with unclear knowledge of their diagnosis. As shown in Table 1, there was no difference in sex composition between participants who knew their diagnosis and those who did not know (women: $99.26 \%$ vs. 99.24\%, $P=0.904)$. Significant differences were found in age, clinical stage, surgery history and reporting hospital grade between patients who knew their diagnosis and those who did not $(P<0.05)$. A trend of informing the patients of their cancer diagnosis was also found by noticing the difference between different phases of the diagnostic year (when participants were diagnosed with breast cancer, 1: before 2006, 2: 2007-2011, 3: 2012-2016; linear-by-linear association: value $=4.232, P=0.040)$. Patients who knew their diagnosis had a younger average age $(55.97 \pm 11.94$ vs. $60.49 \pm 14.20, P<0.001)$, earlier clinical stage (stage $0-\mathrm{I}: 31.94 \%$ vs. $22.28 \%, P<0.001$ ), higher surgery rate $(56.20 \%$ vs. $49.24 \%, P<0.001)$, and more recent diagnostic year (diagnosed from 2012 to $2017: 40.78 \%$ vs. $40.50 \%, P=0.001$ ). In addition, patients registered and reported in higher grade hospitals were more likely to be informed of their diagnosis (high-grade hospital: $57.91 \%$ vs. $55.70 \%, P<0.05)$. 
Table 1 Demographic and clinical characteristics of participants, n(\%)

\begin{tabular}{|c|c|c|c|c|c|}
\hline \multirow[t]{2}{*}{ Variable } & \multirow{2}{*}{$\begin{array}{l}\text { Total } \\
\text { sample } \\
(N=12, \\
327)\end{array}$} & \multicolumn{4}{|c|}{ Knowing status of cancer diagnosis } \\
\hline & & Did Know $(n=9466)$ & Did not know $(n=2756)$ & Unclear $(n=105)$ & $P^{*}$ \\
\hline \multicolumn{6}{|l|}{ Sex } \\
\hline Male & $93(0.74)$ & $70(0.74)$ & $21(0.76)$ & $2(1.90)$ & 0.904 \\
\hline Female & $12,234(99.26)$ & $9396(99.26)$ & 2735(99.24) & 103(98.10) & \\
\hline Average age & $57.10 \pm 12.70$ & $55.97 \pm 11.94$ & $60.49 \pm 14.20$ & $69.52 \pm 15.10$ & $<0.001$ \\
\hline$<35$ & $380(3.08)$ & $305(3.22)$ & $74(2.68)$ & $1(9.52)$ & $<0.001$ \\
\hline $35-$ & 1564(12.69) & 1258(13.29) & 298(10.81) & $8(6.60)$ & \\
\hline $45-$ & $3821(31.00)$ & 3137(33.14) & $672(24.38)$ & 12(7.62) & \\
\hline $55-$ & $3488(28.30)$ & 2762(29.18) & $709(25.72)$ & 17(16.19) & \\
\hline $65-$ & 1789(14.51) & 1289(13.62) & 482(17.49) & 18(17.14) & \\
\hline$\geq 75$ & $1285(10.42)$ & $715(7.55)$ & $521(18.90)$ & $49(46.67)$ & \\
\hline Clinical stage & & & & & $<0.001$ \\
\hline Stage 0- I & $3641(29.54)$ & $3024(31.94)$ & $614(22.28)$ & $3(2.86)$ & \\
\hline Stage II & $3700(30.02)$ & 3037(32.08) & $657(23.84)$ & $6(5.71)$ & \\
\hline Stage Ш & $1135(9.21)$ & $908(9.59)$ & 220(7.98) & $7(6.67)$ & \\
\hline Stage IV & $517(4.19)$ & $358(3.78)$ & 149(5.41) & $10(9.52)$ & \\
\hline Unclassified & $3334(27.05)$ & $2139(22.60)$ & $1116(40.49)$ & 79(75.24) & \\
\hline Surgery history & & & & & $<0.001$ \\
\hline Yes & 6697(54.33) & $5320(56.20)$ & 1357(49.24) & 20(19.05) & \\
\hline No & $5630(45.67)$ & $4146(43.80)$ & 1399(50.76) & 85(80.95) & \\
\hline \multicolumn{6}{|l|}{ Diagnostic year ${ }^{a}$} \\
\hline 1: before 2006 & $3268(26.51)$ & $2442(25.80)$ & $802(29.10)$ & $24(22.86)$ & 0.001 \\
\hline 2: 2007-2011 & 4074(32.83) & 3163(33.41) & $838(30.41)$ & $73(69.52)$ & \\
\hline 3: 2012-2016 & $4985(40.44)$ & $3861(40.78)$ & $1116(40.50)$ & $8(7.62)$ & \\
\hline Hospital grade & & & & & $<0.05$ \\
\hline Primary grade hospital & $166(1.35)$ & 103(1.09) & $45(1.63)$ & 18(17.14) & \\
\hline Middle grade hospital & $5088(41.28)$ & $3881(41.00)$ & $1176(42.67)$ & $31(29.52)$ & \\
\hline High grade hospital & 7073(57.38) & $5482(57.91)$ & 1535(55.70) & $56(53.33)$ & \\
\hline
\end{tabular}

${ }^{*}$ patients who knew diagnosis vs. patients who did not know diagnosis

a Diagnostic year 1 means those being diagnosed before 2006, 2 means those being diagnosed from 2007 to 2011,3 mean those being diagnosed from 2012 to 2016

Univariate analysis of factors influencing the survival time of patients with breast cancer

Altogether, 2152 (17.24\%) deaths occurred among the 12,327 registered patients during the 14-year median follow-up. The 3-year survival rate and 5-year survival rate of our participants were 0.86 and 0.81 , respectively. As shown in Table 2 and Fig. 1, participants with different characteristics had significant differences in prognosis. The 3-year survival rate and 5-year survival rate of patients who knew their diagnosis were both longer than those who did not know (0.89 vs. $0.79,0.85$ vs. $0.73, P<$ $0.001)$. In addition, it was found that female sex $(P=0.011)$, younger age $(<35$ years: $P<0.001)$, earlier clinical stage $(P<0.001)$, higher rate of surgery $(P<0.001)$, being diagnosed more recently $(P<0.001)$ and being reported from higher grade hospitals $(P<0.001)$ contributed to a better survival rate.

\section{Stratified analysis of the impact of cancer diagnosis} knowledge on survival time in patients with breast cancer As shown in Table 3 and Additional file 3, participants were stratified by sex, age, clinical stage, surgery history, diagnostic year and grade of reporting hospital to explore the relationship between awareness of cancer diagnosis and prognosis. Except for the subgroups of male patients $(P=0.103)$ and stage $\amalg$ patients $(P=0.265)$, patients who knew their cancer diagnosis displayed a better survival rate than those who did not $(P<0.05)$. 
Table 2 Survival of breast cancer patients with different characteristics

\begin{tabular}{|c|c|c|c|c|}
\hline Variable & Death number/Total number & 3-year survival rate & 5-year survival rate & $P^{*}$ \\
\hline Knowing status of cancer diagnosis ${ }^{a}$ & & & & $<0.001$ \\
\hline Did know & $1446 / 9466$ & 0.89 & 0.85 & \\
\hline Did not know & $778 / 2756$ & 0.79 & 0.73 & \\
\hline Sex & & & & 0.011 \\
\hline Male & 29/93 & 0.78 & 0.70 & \\
\hline Female & $2300 / 12234$ & 0.86 & 0.81 & \\
\hline Age (years) & & & & $<0.001$ \\
\hline$<45$ & 259/1944 & 0.90 & 0.87 & \\
\hline $45-$ & $543 / 3821$ & 0.90 & 0.86 & \\
\hline $55-$ & $473 / 3488$ & 0.89 & 0.86 & \\
\hline $65-$ & $408 / 1789$ & 0.85 & 0.78 & \\
\hline$\geq 75$ & $646 / 1285$ & 0.62 & 0.51 & \\
\hline Clinical stage ${ }^{b}$ & & & & $<0.001$ \\
\hline Stage $0-1$ & $197 / 3640$ & 0.97 & 0.95 & \\
\hline Stage $\|$ & $480 / 3700$ & 0.92 & 0.88 & \\
\hline Stage Ш & $316 / 1136$ & 0.78 & 0.70 & \\
\hline Stage IV & $358 / 517$ & 0.44 & 0.33 & \\
\hline Surgery history & & & & $<0.001$ \\
\hline Yes & $890 / 6697$ & 0.91 & 0.87 & \\
\hline No & $1439 / 5630$ & 0.80 & 0.75 & \\
\hline \multicolumn{5}{|l|}{ Diagnostic year $^{c}$} \\
\hline 1: before 2006 & $1164 / 3268$ & 0.82 & 0.76 & $<0.001$ \\
\hline 2: 2007-2011 & $815 / 4074$ & 0.86 & 0.82 & \\
\hline 3: 2012-2016 & $350 / 4985$ & 0.91 & 0.89 & \\
\hline Hospital grade & & & & $<0.001$ \\
\hline Primary grade hospital & $95 / 166$ & 0.47 & 0.41 & \\
\hline Middle grade hospital & $972 / 5088$ & 0.86 & 0.82 & \\
\hline High grade hospital & $1262 / 7073$ & 0.87 & 0.82 & \\
\hline
\end{tabular}

"overall comparison of survival curves in subgroups

${ }^{a}$ patients with unclear knowing status of cancer diagnosis were not included

b patients with unclassified clinical stage were not included

' Diagnostic year 1 means those being diagnosed before 2006, 2 means those being diagnosed from 2007 to 2011, 3 mean those being diagnosed from 2012

to 2016

\section{Multivariate analysis of factors influencing the survival} time of patients with breast cancer

Knowledge of cancer diagnosis status, age, surgery history, reporting hospital grade, diagnostic year and clinical stage were independent influencing factors of the survival time of patients with breast cancer $(P<$ 0.001 , Table 4 ). The results showed that not knowing of the cancer diagnosis was significantly associated with a poor prognosis compared to knowing (HR, 1.405, 95\% CI, 1.285-1.537, $P<0.001)$. Having surgery contributed to a better survival (HR, 0.647,95\% CI, 0.594-0.706; $P<$ $0.001)$, while age was a risk factor for survival time (HR, 1.434,95\% CI, 1.285-1.537; $P<0.001)$. Compared to patients from primary grade hospitals, patients from higher grade hospitals had a better survival rate (HR, 0.457, and 0.478 , respectively; $P<0.001)$. The more recently the patients were diagnosed, the longer they were likely to survive (HR, 0.802, and 0.649, respectively; $P<0.001$, Table 4). In addition, compared to stage 0- I patients, more advanced stage patients had a poorer prognosis (HR, 2.085, 4.988, and 13.953, respectively; $P<0.001$, Table 4).

The impact of cancer diagnosis knowledge on survival time in patients with breast cancer after PSM

After PSM, 2694 pairs (2694 patients who knew their diagnosis and 2694 patients who did not) were selected from 9466 patients who knew their diagnosis and 2756 


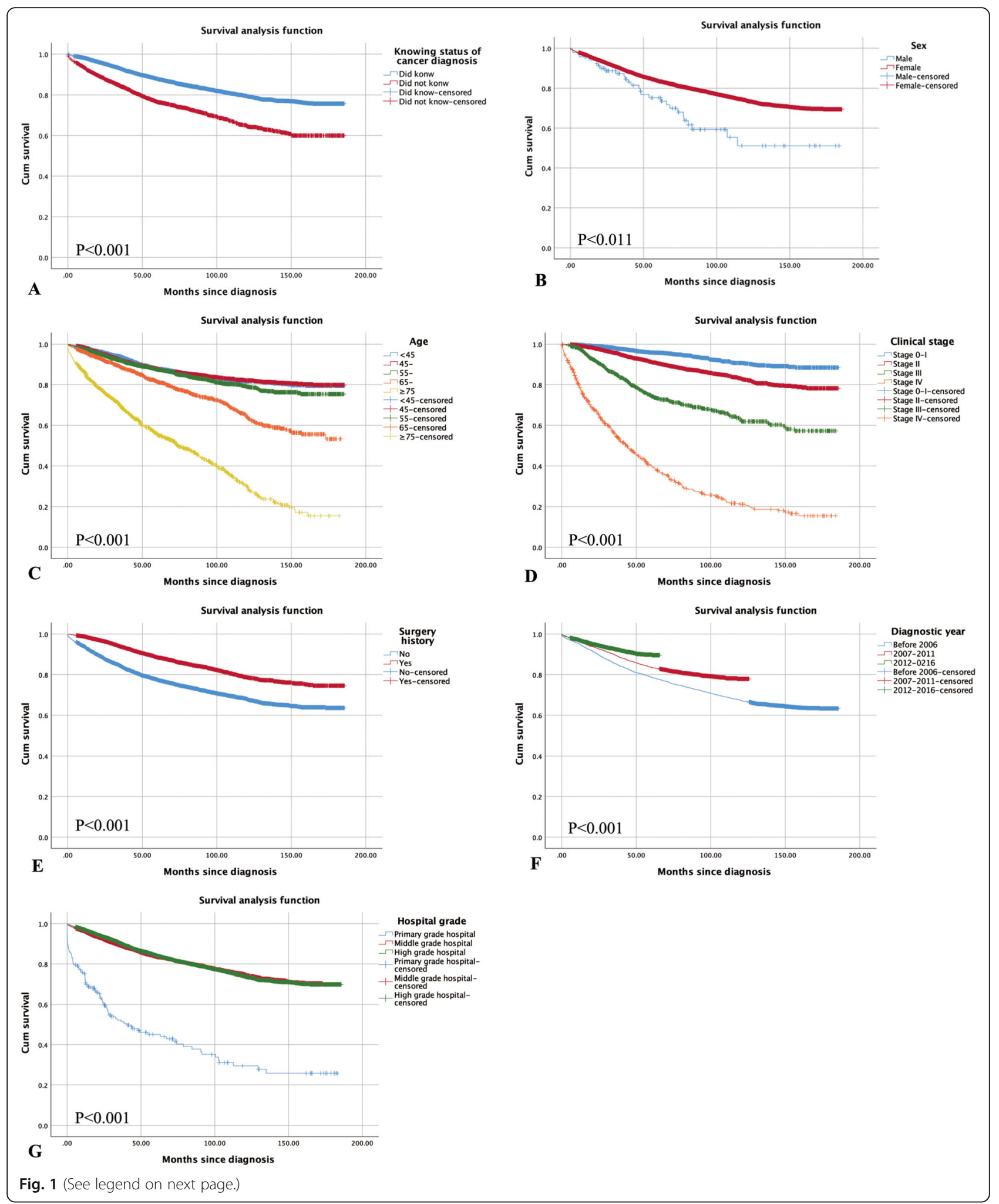


(See figure on previous page.)

Fig. 1 Survival of breast cancer patients with different characteristics. A, the patients knew their cancer diagnosis vs. those did not know; B, the male patients vs. the female patients; $\mathbf{C}$, the patients younger than 45 vs. those aging from $45-55$ vs. those aging from $55-65$ vs. those aging from $65-75$ vs. those older than $75 ; \mathbf{D}$, the patients at stage 0 -I vs. those at stage II vs. those at stage III vs. those at stage IV; $\mathbf{E}$, the patients without surgery history vs. those with surgery history; $\mathbf{F}$, the patients diagnosed before 2006 vs. those diagnosed between 2007-2011 vs. those diagnosed between 2012-2016; G, the patients reported from primary grade hospital vs. those reported from middle grade hospital vs. those reported from high grade hospital

patients who did not. Both the 3-year survival rate and 5 -year survival rate of patients who knew their diagnosis were longer than those who did not know ( 0.84 vs. 0.80 , 0.79 vs. $0.74 ; P<0.001$, Table 5, Fig. 2 ).

\section{Discussion}

According to our long-term follow-up research of a large sample, disclosure of patients' diagnosis was found to be a protective factor for the longer survival time of patients with breast cancer through univariate and multivariate analyses. Age, clinical stage, surgery history and diagnosis year were also associated with patient survival time.

The disclosure of cancer diagnosis to patients with breast cancer has always been a contentious topic worldwide. Owing to the different cultural backgrounds of different countries, the opinions on this topic are varied. A survey indicated that in the United Kingdom, almost

Table 3 Relationship between cancer awareness and survival time of breast cancer patients by stratified analysis

\begin{tabular}{|c|c|c|c|c|c|}
\hline \multirow[t]{2}{*}{ Stratified factors } & \multicolumn{2}{|l|}{ 3-year survival rate } & \multicolumn{2}{|l|}{ 5-year survival rate } & \multirow[t]{2}{*}{$P^{*}$} \\
\hline & $\begin{array}{l}\text { Did know cancer } \\
\text { diagnosis }\end{array}$ & $\begin{array}{l}\text { Did not know } \\
\text { cancer diagnosis }\end{array}$ & $\begin{array}{l}\text { Did know cancer } \\
\text { diagnosis }\end{array}$ & $\begin{array}{l}\text { Did not know } \\
\text { cancer diagnosis }\end{array}$ & \\
\hline \multicolumn{6}{|l|}{ Sex } \\
\hline Male & 0.85 & 0.66 & 0.76 & 0.58 & 0.103 \\
\hline Female & 0.89 & 0.79 & 0.85 & 0.73 & $<0.001$ \\
\hline \multicolumn{6}{|l|}{ Age (years) } \\
\hline$<45$ & 0.92 & 0.87 & 0.88 & 0.82 & $<0.001$ \\
\hline $45-$ & 0.91 & 0.86 & 0.87 & 0.82 & $<0.001$ \\
\hline $55-$ & 0.91 & 0.85 & 0.87 & 0.81 & $<0.001$ \\
\hline $65-$ & 0.89 & 0.79 & 0.82 & 0.73 & $<0.001$ \\
\hline$\geq 75$ & 0.70 & 0.56 & 0.60 & 0.45 & $<0.001$ \\
\hline \multicolumn{6}{|l|}{ Clinical stage ${ }^{a}$} \\
\hline Stage 0- I & 0.97 & 0.95 & 0.96 & 0.91 & $<0.001$ \\
\hline Stage ॥ & 0.93 & 0.89 & 0.89 & 0.85 & 0.001 \\
\hline Stage Ш & 0.79 & 0.76 & 0.71 & 0.69 & 0.265 \\
\hline Stage IV & 0.47 & 0.40 & 0.34 & 0.31 & 0.005 \\
\hline Unclassified & 0.84 & 0.70 & 0.79 & 0.63 & $<0.001$ \\
\hline \multicolumn{6}{|l|}{ Surgery history } \\
\hline Yes & 0.92 & 0.87 & 0.88 & 0.82 & $<0.001$ \\
\hline No & 0.85 & 0.70 & 0.81 & 0.63 & $<0.001$ \\
\hline \multicolumn{6}{|l|}{ Diagnostic year ${ }^{b}$} \\
\hline 1: before 2006 & 0.85 & 0.73 & 0.80 & 0.67 & $<0.001$ \\
\hline 2: 2007-2011 & 0.90 & 0.80 & 0.86 & 0.75 & $<0.001$ \\
\hline 3: 2012-2016 & 0.93 & 0.84 & 0.92 & 0.81 & $<0.001$ \\
\hline \multicolumn{6}{|l|}{ Hospital grade } \\
\hline Primary grade hospital & 0.60 & 0.36 & 0.52 & 0.36 & 0.034 \\
\hline Middle grade hospital & 0.89 & 0.78 & 0.86 & 0.71 & $<0.001$ \\
\hline High grade hospital & 0.89 & 0.81 & 0.85 & 0.75 & $<0.001$ \\
\hline
\end{tabular}

* overall comparison of survival curves in subgroups

a patients with unclear knowing status of cancer diagnosis were not included

b Diagnostic year 1 means those being diagnosed before 2006, 2 means those being diagnosed from 2007 to 2011 , 3 mean those being diagnosed from 2012 to 2016 
Table 4 Factors influencing survival time of breast cancer patients by Cox proportional hazard regression model $(n=12,327)$

\begin{tabular}{|c|c|c|c|c|}
\hline Variable & B & SE & $\mathrm{HR}(95 \% \mathrm{Cl})$ & $P$ \\
\hline \multicolumn{5}{|c|}{ Knowing status of cancer diagnosis } \\
\hline Did know & & & 1.00 & $<0.001$ \\
\hline Didn't know & 0.34 & 0.05 & $1.41(1.29-1.54)$ & $<0.001$ \\
\hline Unclear & 1.61 & 0.11 & $5.02(4.05-6.22)$ & $<0.001$ \\
\hline Age & 0.36 & 0.02 & $1.43(1.39-1.48)$ & $<0.001$ \\
\hline Surgery history & -0.44 & 0.04 & $0.65(0.59-0.71)$ & $<0.001$ \\
\hline \multicolumn{5}{|l|}{ Hospital grade } \\
\hline Primary grade hospital & & & 1.00 & $<0.001$ \\
\hline Middle grade hospital & -0.78 & 0.11 & $0.46(0.37-0.57)$ & $<0.001$ \\
\hline High grade hospital & -0.74 & 0.11 & $0.48(0.39-0.60)$ & $<0.001$ \\
\hline \multicolumn{5}{|l|}{ Diagnostic year ${ }^{a}$} \\
\hline 1: before 2006 & & & 1.00 & $<0.001$ \\
\hline 2: 2007-2011 & -0.22 & 0.05 & $0.80(0.73-0.88)$ & $<0.001$ \\
\hline 3: 2012-2016 & -0.43 & 0.07 & $0.65(0.59-0.71)$ & $<0.001$ \\
\hline \multicolumn{5}{|l|}{ Clinical Stage } \\
\hline Stage 0- I & & & 1.00 & $<0.001$ \\
\hline Stage II & 0.74 & 0.09 & $2.09(1.77-2.46)$ & $<0.001$ \\
\hline Stage Ш & 1.61 & 0.09 & $4.99(4.17-5.96)$ & $<0.001$ \\
\hline Stage IV & 2.64 & 0.09 & 13.95(11.70-16.64) & $<0.001$ \\
\hline Unclassified & 1.37 & 0.08 & $3.94(3.37-4.60)$ & $<0.001$ \\
\hline
\end{tabular}

$H R$ hazard ratio, $\mathrm{Cl}$ confidence interval

a Diagnostic year 1 means those being diagnosed before 2006, 2 means those being diagnosed from 2007 to 2011, 3 mean those being diagnosed from 2012 to 2016

all patients wanted to be aware of their diagnosis, while in Asian culture, physicians and family members may worry more about whether to inform patients [29]. Moreover, there was a change in attitude when the hypothetical diagnosis changed from the initial stage to the terminal stage. The percentage of those who wanted to reveal the diagnosis to patients decreased significantly (from 87.5 to $40.5 \%$ ) [30]. The reasons why physicians and family members hesitate to disclose this information to patients may include the psychological impact and pain from treatment patients undergo, especially the loss of physical integrity. It has been suggested that losing a breast by mastectomy could bring about severe mental impairments resulting from body image, female identity, self-worth, social interactions and so on [31].
In this study, we found that the popularization of informing patients of their diagnosis is increasing year by year, and the disclosure of patients' diagnosis is an independent protective factor for patients with breast cancer to prolong their survival time. Patients not knowing of their real condition may have unrealistic optimism, which may lead to an unhealthy lifestyle, making their condition worse. In contrast, having a clear perspective of their cancer status may lead to a healthier way of life. Informing patients with breast cancer as early as possible assists them in obtaining precise knowledge of themselves. Moreover, there are many strategies to help patients cope with their emotional distress such as psychological care and breast reconstruction, which have already had some effectiveness [32, 33].

Table 5 Survival of breast cancer patients knowing or not knowing diagnosis, before and after propensity score matching

\begin{tabular}{|c|c|c|c|c|c|c|c|c|}
\hline \multirow[t]{2}{*}{ Variable } & \multicolumn{4}{|l|}{ Before PSM } & \multicolumn{4}{|l|}{ After PSM } \\
\hline & $\begin{array}{l}\text { Death number/ } \\
\text { Total number }\end{array}$ & $\begin{array}{l}\text { 3-year } \\
\text { survival rate }\end{array}$ & $\begin{array}{l}\text { 5-year } \\
\text { survival rate }\end{array}$ & $P^{*}$ & $\begin{array}{l}\text { Death number/ } \\
\text { Total number }\end{array}$ & $\begin{array}{l}\text { 3-year } \\
\text { survival rate }\end{array}$ & $\begin{array}{l}\text { 5-year } \\
\text { survival rate }\end{array}$ & $P^{*}$ \\
\hline $\begin{array}{l}\text { Knowing status of } \\
\text { cancer diagnosis }\end{array}$ & & & & $<0.001$ & & & & $<0.001$ \\
\hline Did know & $1446 / 9466$ & 0.89 & 0.85 & & $700 / 2694$ & 0.84 & 0.79 & \\
\hline Did not know & $778 / 2756$ & 0.79 & 0.73 & & $597 / 2694$ & 0.80 & 0.74 & \\
\hline
\end{tabular}

*overall comparison of survival curves in subgroups

${ }^{a}$ patients with unclear knowing status of cancer diagnosis were not included 


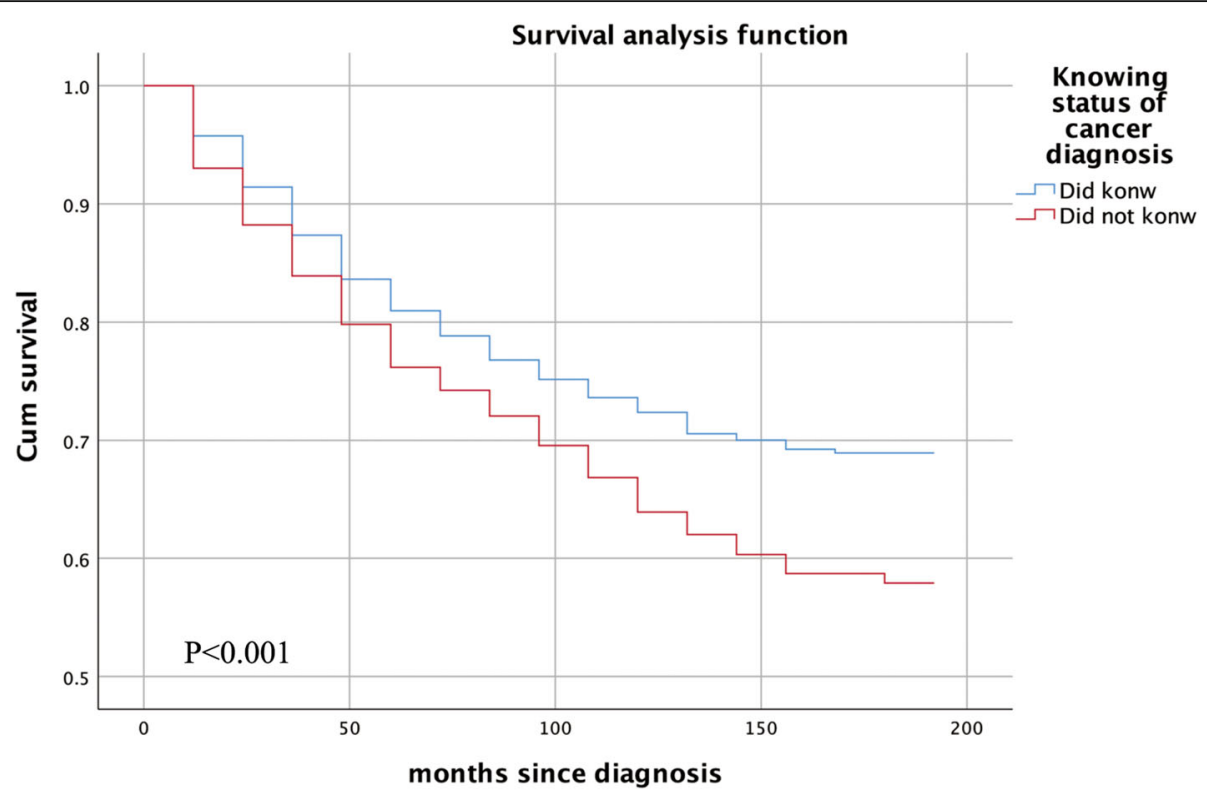

Fig. 2 Difference of survival time between patients knowing their diagnosis and patients not of breast cancer patients after PSM. A, the patients knew their cancer diagnosis vs. those did not know

In the male patient subgroup, diagnostic disclosure was not linked with survival time. Male breast cancer is uncommon, and only $93(0.75 \%)$ male patients were involved in our study. Similarly, there were $2470(0.98 \%)$ men with breast cancer and 252,710 women with breast cancer in 2017 in the USA [34]. Since most data for breast cancer research are from female patients, men tend to be diagnosed with breast cancer at a later age than women since most treatment and diagnostic decisions are made based on female patients' data [35]. In addition, breast cancer appeared in female patients more frequently, therefore, male patients may undergo a special perceptual experience. Because of the sex stereotype, male patients knowledgeable of their diagnosis were more likely to have a high level of cancer-specific distress and depressive symptoms [36]. More research may be needed on the psychological state of this particular and rare group.

Our study found that disclosure of cancer status and other factors, such as female sex, younger age, earlier clinical stage, surgery history, and more recent diagnostic year, were significantly related to better survival. As shown in Additional file 4, patients without surgery history were less likely to be aware of their cancer condition (did not know: $25.23 \%$ vs. $20.32 \%$ ), as were patients with a later clinical stage (stage IV: $5.75 \%$ vs. $2.88 \%$ ), those with an earlier diagnostic year (diagnosis before 2006: $35.68 \%$ vs. $18.80 \%$ ) and those with a lower hospital grade (primary and middle grade hospitals: $1.85 \%$ vs. 0.92 and $45.93 \%$ vs. $37.36 \%, P<0.05)$. There are several possible reasons for this result. Patients who had no idea of their diagnosis could hardly have a clear understanding of their treatment, which decreased their surgery rate. Patients at later clinical stages such as stage IV, were not advocated to undergo a surgery because of their conditions. In addition, the conditions for performing surgery in primary hospitals may not have been complete in earlier times, which may also limit the chances of surgery. A more recent diagnostic year predicts a shorter time of cancer to development and more advanced treatment. Meanwhile, more patients were told of their cancer status in the more recent diagnostic years. Therefore, patients with these conditions may have a better prognosis.

In our study, we used a narrow definition of cancer disclosure, focusing only on whether the patient was informed of their cancer diagnosis and not considering the patient's knowledge of treatment, prognosis, and other relevant information. We did not obtain detailed information about the treatment that participants received, which may have influenced the final results of the participants. Because of challenges in data collection and uncertainty, some potential factors, such as the psychological condition of patients, education level and income, were not included. In future research, patients might be concerned about their own conditions; however, the decision the patients' families made at the first diagnosis may reflect the patients' characteristics to some extent. Therefore, we regarded their diagnosis as concealed if they did not know their own condition when they were enrolled in our study. Since our follow-up lasted for a long time, some participants might have known about their condition after discharge from the hospital because 
of personal perception or other reasons. However, this phenomenon did not mean that our classification of the status of whether the diagnosis was known was inappropriate. According to the Shanghai Cancer Patient Follow-up Manual, the information of patients who were unaware of their cancer status would be obtained from follow up by their families, and patients who were aware of their diagnosis would provide the information by themselves. Since we made the first classification according to the hospitalization medical record, we recorded whether the medical staff at that time had informed the patient of their cancer status. The hospitalization medical record was given certain legal validity, which means that we could not change the classification due to this unsteady state. The establishment of a prospective cohort and further research on the basis of the current study will help solve this problem.

The Cox regression analysis showed that 105 patients with uncertain knowledge status of cancer diagnosis had a 5 times higher risk of death than those who knew about their cancer diagnosis. These 105 patients were older (average age: $69.52 \pm 15.10$ years, $\geq 75$ years: $46.67 \%$ ), and mostly had an unclassified clinical stage (75.24\%). Most of them did not undergo surgery (80.95\%) and were diagnosed before 2011 (92.38\%) (Table 1). Older patients have a greater dependency on their guardians, which made their information less clear to medical staff. Patients with an unclassified stage hardly underwent surgeries, and some of them had only been hospitalized for a short time at a late clinical stage (Additional file 5). In addition, being diagnosed earlier and attending a hospital with a lower grade may mean an incomplete registration system for personal information and outdated treatment. These factors may contribute to a higher risk of death.

This retrospective cohort study provides clear evidence to promote diagnostic disclosure to breast cancer patients through the long-term follow-up of a large sample size, which hopefully offers a new direction in clinical practice.

Our study suggested that an increasing number of medical staff and patients' families are more willing to disclose the truth to patients according to our analysis on diagnostic year, which implies that knowledge of the cancer status predicts a better prognosis and a longer survival time than not knowing. Positive evidence suggests that disclosing the diagnosis to patients is better for the survival of patients with breast cancer. Previous studies showed that most patients were ready to have sufficient knowledge of their diagnosis, while the majority of medical staff and families were not [37] The reason for this phenomenon may be that it is a difficult task to reveal the cancer diagnosis to patients, which would make physicians feel uncomfortable and unprepared [38, 39]. With the consent right becoming ever more common, the debate about whether to tell patients about their diagnosis would be replaced by how and when to tell them about their diagnosis. Existing guidelines for breaking bad news based on expert opinion are available [40]. However, some guidelines were not completely derived from empirical data [41]. Therefore, formal guidelines for breaking bad news must be made. Furthermore, oncological care for patients is also needed to help them maintain a positive attitude towards their cancer status and overcome their emotional distress [42].

In this study, we did not obtain the detailed treatments received by the participants, which is a major restrictive factor. Different treatments might result in different prognosis and make variety impacts on patients. Because of challenges in data collection and uncertainty, some potential factors were not included, such as household income, education level and psychological condition of patients, which are also study limitations.

\section{Conclusions}

Based on the long-term follow-up of a large sample, the popularization of the disclosure of the cancer diagnosis to patients has increased over time, which may contribute to a longer survival time in patients with breast cancer. Even though being told of their cancer status may arouse emotional distress in patients, with more adequate information on their condition and better skills of medical staff to disclose this information, patients would benefit from knowing this information in the long term. Formal guidelines of medical staff to reveal cancer diagnosis and education for patients' families of psychological care need further complement in clinical practice. Our findings provide further evidence supporting the disclosure of the cancer diagnosis to patients. Future prospective studies are needed to validate these findings.

\section{Abbreviations}

PSM: Propensity score matching; NCl: National Cancer Institute; SEER: Surveillance, Epidemiology, and End Results; MV\%: Morphological verification; DCO\%: Death certification only; M/I: Mortality-to-incidence ratio; ANOVA: One-way analysis of variance; HRs: Hazard ratios; Cls: Confidence intervals; PSs: Propensity scores

\section{Supplementary Information}

The online version contains supplementary material available at https://doi. org/10.1186/s12885-021-08512-1. Additional file 1. Shanghai Cancer Report Card.
Additional file 2. Plot to check proportional hazards assumption of the
Cox model.

Additional file 3. Survival time of breast cancer patients knowing and not knowing diagnosis by stratified analysis.

Additional file 4. Demographic and clinical characteristics of patients with or without surgery history.

Additional file 5. Demographic and clinical characteristics of participants with unclassified clinical stage. 


\section{Authors' contributions}

TS and XPL conceived and designed the study. CH WXZ, YXT, YHB, ZL and $X P L$ acquired the data. $\mathrm{CH}$, JFX and TS analyzed the data. The first draft of the manuscript was written by CH. HW, SYX, JZX, LX, RKZ, YJW, JD and YJH have substantively revised the manuscript. All authors have approved the submitted version and have agreed both to be personally accountable for the author's own contributions. And all authors ensured that questions related to the accuracy or integrity of any part of the work, even ones in which the author was not personally involved, were appropriately investigated, resolved, and the resolution documented in the literature.

\section{Funding}

This study was funded by National Science Foundation of China (Grant number 81602734), Military Medical Science and Technology Youth Cultivation Plan (Grant number 2019QNP014), Military Research Project (Grant number GWS20J007) and National Social Science Foundation of China (Grant number 17ZDA327).

\section{Availability of data and materials}

The datasets used and analysed during the current study are available from the corresponding author on reasonable request.

\section{Declarations}

\section{Ethics approval and consent to participate}

All procedures performed in studies involving human participants were in accordance with the ethical standards of the institutional committee and with the 1964 Helsinki Declaration and its later comparable ethical standards. This study was approved by the Medical Research Ethics Committee of Fudan University (No. IRB\#2016-04-0586), and the author XPL obtained a permission from the Pudong Center for Disease Control to use patients' data. Written informed consent was obtained from the participants or their families and the written informed consent to participate of participant under the age of 16 was obtained from the parents or legal guardians.

\section{Consent for publication}

Written informed consent for publication of their clinical details was obtained from the patient/parent/legal guardian/ relative of the patient. A copy of the consent form is available for review by the Editor of this journal.

\section{Competing interests}

The authors declare that they have no competing interests.

\section{Author details}

${ }^{1}$ Department of Medical Psychology, College of Psychology, Naval Medical University, 800 Xiangyin Rd, Shanghai 200433, China. ${ }^{2}$ School of Nursing and Health Management, Shanghai University of Medicine \& Health Sciences, Shanghai, China. ${ }^{3}$ Department of Medical Psychology, Changzheng Hospital Affiliated to Naval Medical University, Shanghai, China. ${ }^{4}$ Zhoupu Hospital affiliated to Shanghai University of Medicine \& Health Sciences, Shanghai, China. ${ }^{5}$ Department of Health Statistics, Naval Medical University, Shanghai, China. ${ }^{6}$ Department of Cancer Prevention and Vital Statistics, Center for Disease Control and Prevention, Pudong New Area, Shanghai, China.

${ }^{7}$ Pudong Institute of Preventive Medicine, Fudan University, Shanghai, China.

Received: 15 October 2020 Accepted: 15 June 2021

Published online: 27 June 2021

\section{References}

1. Ferlay J, Soerjomataram I, Dikshit R, Eser S, Mathers C, Rebelo M, et al. Cancer incidence and mortality worldwide: sources, methods and major patterns in GLOBOCAN 2012. Int J Cancer. 2015;136(5):E359-E86. https://doi. org/10.1002/ijc.29210.

2. Guo F, Kuo YF, Shih YCT, Giordano SH, Berenson AB. Trends in breast cancer mortality by stage at diagnosis among young women in the United States. Cancer. 2018;124(17):3500-9. https://doi.org/10.1002/cncr.31638.

3. Torre LA, Bray F, Siegel RL, Ferlay J, Lortet-Tieulent J, Jemal A. Global cancer statistics, 2012. CA Cancer J Clin. 2015;65(2):87-108. https://doi.org/10.3322/ caac. 21262.

4. Fan L, Zheng Y, Yu KD, Liu GY, Wu J, Lu JS, et al. Breast cancer in a transitional society over 18 years: trends and present status in Shanghai,
China. Breast Cancer Res Treat. 2009;117(2):409-16. https://doi.org/10.1007/ s10549-008-0303-z.

5. Fan L, Strasser-Weippl K, Li JJ, St Louis J, Finkelstein DM, Yu KD, et al. Breast cancer in China. Lancet Oncol. 2014;15(7):e279-89. https://doi.org/10.1016/ S1470-2045(13)70567-9.

6. Linos E, Spanos D, Rosner BA, Linos K, Hesketh T, Qu JD, et al. Effects of reproductive and demographic changes on breast cancer incidence in China: a modeling analysis. J Natl Cancer Inst. 2008;100(19):1352-60. https:// doi.org/10.1093/jnci/djn305.

7. Xu YL, Sun Q, Shan GL, Zhang J, Liao HB, Li SY, et al. A case-control study on risk factors of breast cancer in China. Arch Med Sci. 2012;8(2):303-9. https://doi.org/10.5114/aoms.2012.28558.

8. Bao PP, Shu XO, Gao YT, Zheng Y, Cai H, Deming SL, et al. Association of hormone-related characteristics and breast cancer risk by estrogen receptor/progesterone receptor status in the shanghai breast cancer study. Am J Epidemiol. 2011;174(6):661-71. https://doi.org/10.1093/aje/kwr145.

9. Yanhua C, Geater A, You J, Li L, Shaoqiang Z, Chongsuvivatwong V, et al. Reproductive variables and risk of breast malignant and benign tumours in Yunnan province, China. Asian Pac J Cancer Prev. 2012;13(5):2179-84. https://doi.org/10.7314/APJCP.2012.13.5.2179.

10. Zhang Q, Liu LY, Wang F, Mu K, Yu ZG. The changes in female physical and childbearing characteristics in China and potential association with risk of breast cancer. BMC Public Health. 2012;12(1):368. https://doi.org/10.1186/14 71-2458-12-368

11. Shu XO, Jin F, Dai Q, Shi JR, Potter JD, Brinton LA, et al. Association of body size and fat distribution with risk of breast cancer among Chinese women. Int J Cancer. 2001;94(3):449-55. https://doi.org/10.1002/ijc.1487.

12. $\mathrm{Ng}$ EH, Gao F, Ji CY, Ho GH, Soo KC. Risk factors for breast carcinoma in Singaporean Chinese women: the role of central obesity. Cancer. 1997;80(4): 725-31. https://doi.org/10.1002/(SICI)1097-0142(19970815)80:4<725::AIDCNCR11>3.0.CO;2-V.

13. Northouse LL, Swain MA. Adjustment of patients and husbands to the initial impact of breast cancer. Nurs Res. 1987;36(4):221-5.

14. Stanton AL, Snider PR. Coping with a breast cancer diagnosis: a prospective study. Health Psychol. 1993;12(1):16-23. https://doi.org/10.1037/0278-6133.12.1.16.

15. Vinokur AD, Threatt BA, Vinokur-Kaplan D, Satariano WA. The process of recovery from breast cancer for younger and older patients. Changes during the first year. Cancer. 1990;65(5):1242-54. https://doi.org/10.1002/1 097-0142(19900301)65:5<1242::AID-CNCR2820650535>3.0.CO;2-1.

16. Abebe $\mathrm{E}$, Abebe $\mathrm{H}$. Types of cancers diagnosed and the preference of families of adult patients with Cancer about disclosing diagnosis to the patients. Ethiop J Health Sci. 2017;27(3):255-62. https://doi.org/10.4314/ejhs. v27i3.7.

17. Atesci FC, Baltalarli B, Oguzhanoglu NK, Karadag F, Ozdel O, Karagoz N. Psychiatric morbidity among cancer patients and awareness of illness. Support Care Cancer. 2004;12(3):161-7. https://doi.org/10.1007/s00520-003-0585-y.

18. Tavoli A, Mohagheghi MA, Montazeri A, Roshan R, Tavoli Z, Omidvari S. Anxiety and depression in patients with gastrointestinal cancer: does knowledge of cancer diagnosis matter? BMC Gastroenterol. 2007;7(1):28. https://doi.org/10.1186/1471-230X-7-28.

19. Waters EA, Klein WM, Moser RP, Yu M, Waldron WR, McNeel TS, et al. Correlates of unrealistic risk beliefs in a nationally representative sample. J Behav Med. 2011;34(3):225-35. https://doi.org/10.1007/s10865-010-9303-7.

20. Leckie J. The effects of informational intervention on state anxiety and satisfaction in patients undergoing bone scan. Nucl Med Commun. 1994; 15(11):921-7. https://doi.org/10.1097/00006231-199411000-00011.

21. Montgomery C, Lydon A, Lloyd K. Psychological distress among cancer patients and informed consent. J Psychosom Res. 1999;46(3):241-5. https:// doi.org/10.1016/S0022-3999(98)00089-0.

22. Zheng Y, Lei F, Liu B. Cancer diagnosis disclosure and quality of life in elderly cancer patients. Healthcare (Basel). 2019;7(4):163.

23. Su T, He C, Li X, Xiao L, He J, Bai Y, et al. Association between early informed diagnosis and survival time in patients with lung cancer. Psychooncology. 2020;29(5):878-85. https://doi.org/10.1002/pon.5360.

24. Cente NC. Chinese guideline for Cancer registration [in Chinese]. Beijing, China: People's Medical Publishing House Co, LTD; 2016.

25. Curado MP, Edwards B, Shin HR, Storm H, Boyle P. Cancer incidence in five continents, volume ix. larc Scientific Publications. 2008;(160):1-837.

26. Chen W, Zheng R, Zhang S, Zeng H, Xia C, Zuo T, et al. Cancer incidence and mortality in China, 2013. Cancer Lett. 2017;401:63-71. https://doi.org/1 0.1016/j.canlet.2017.04.024 
27. Li X, Deng Y, Tang W, Sun Q, Chen Y, Yang C, et al. Urban-rural disparity in Cancer incidence, mortality, and survivals in Shanghai, China, during 2002 and 2015. Front Oncol. 2018;8:579. https://doi.org/10.3389/fonc.2018.00579.

28. Rosenbaum PR, Rubin DB. The central role of the propensity score in observational studies for causal effects. Biometrika. 1983;70(1):41-55. https:// doi.org/10.1093/biomet/70.1.41.

29. Jenkins V, Fallowfield L, Saul J. Information needs of patients with cancer: results from a large study in UK cancer centres. Br J Cancer. 2001;84(1):4851. https://doi.org/10.1054/bjoc.2000.1573.

30. Jiang Y, Li JY, Liu C, Huang MJ, Zhou L, Li M, et al. Different attitudes of oncology clinicians toward truth telling of different stages of cancer. Support Care Cancer. 2006;14(11):1119-25. https://doi.org/10.1007/s00520006-0071-4.

31. Schover LR. The impact of breast cancer on sexuality, body image, and intimate relationships. CA Cancer J Clin. 1991;41(2):112-20. https://doi.org/1 $0.3322 /$ canjclin.41.2.112.

32. Jiang Y, Liu C, Li JY, Huang MJ, Yao WX, Zhang R, et al. Different attitudes of Chinese patients and their families toward truth telling of different stages of cancer. Psychooncology. 2007;16(10):928-36. https:// doi.org/10.1002/pon.1156

33. Schmidt UL, Wetzel CM, Lange KW, Heine N, Ortmann O. Patients' experience of breast reconstruction after mastectomy and its influence on postoperative satisfaction. Arch Gynecol Obstet. 2017;296(4):827-34. https:// doi.org/10.1007/s00404-017-4495-5.

34. Siegel RL, Miller KD, Jemal A. Cancer statistics, 2017. CA Cancer J Clin. 2017; 67(1):7-30. https://doi.org/10.3322/caac.21387.

35. Korde LA, Zujewski JA, Kamin L, Giordano S, Domchek S, Anderson WF, et al. Multidisciplinary meeting on male breast cancer: summary and research recommendations. J Clin Oncol. 2010;28(12):2114-22. https://doi. org/10.1200/JCO.2009.25.5729.

36. Fentiman IS. Unmet needs of men with breast cancer. Eur J Surg Oncol. 2018;44(8):1123-6. https://doi.org/10.1016/j.ejso.2018.05.004.

37. Kazdaglis GA, Arnaoutoglou C, Karypidis D, Memekidou G, Spanos G Papadopoulos O. Disclosing the truth to terminal cancer patients: a discussion of ethical and cultural issues. East Mediterr Health J. 2010;16(4): 442-7. https://doi.org/10.26719/2010.16.4.442.

38. Baile WF, Buckman R, Lenzi R, Glober G, Beale EA, Kudelka AP. SPIKES-A sixstep protocol for delivering bad news: application to the patient with cancer. Oncologist. 2000;5(4):302-11. https://doi.org/10.1634/theoncologist. 5-4-302.

39. Lamba S, Tyrie LS, Bryczkowski S, Nagurka R. Teaching surgery residents the skills to communicate difficult news to patient and family members: a literature review. J Palliat Med. 2016;19(1):101-7. https://doi.org/10.1089/ jpm.2015.0292.

40. Abdul Hafidz MI, Zainudin LD. Breaking bad news: an essential skill for doctors. Med J Malaysia. 2016;71(1):26-7.

41. Mirza RD, Ren M, Agarwal A, Guyatt GH. Assessing patient perspectives on receiving bad news: a survey of 1337 patients with life-changing diagnoses. AJOB Empir Bioeth. 2019;10(1):36-43. https://doi.org/10.1080/23294515.201 8.1543218 .

42. Nipp RD, Greer JA, El-Jawahri A, Moran SM, Traeger L, Jacobs JM, et al. Coping and prognostic awareness in patients with advanced Cancer. J Clin Oncol. 2017;35(22):2551-7. https://doi.org/10.1200/JCO.2016.71.3404.

\section{Publisher's Note}

Springer Nature remains neutral with regard to jurisdictional claims in published maps and institutional affiliations.

Ready to submit your research? Choose BMC and benefit from:
- fast, convenient online submission
- thorough peer review by experienced researchers in your field
- rapid publication on acceptance
- support for research data, including large and complex data types
- gold Open Access which fosters wider collaboration and increased citations
- maximum visibility for your research: over 100M website views per year
At BMC, research is always in progress.
Learn more biomedcentral.com/submissions

